\section{Diabetic retinopathy: an end of the century perspective}

In 1978 the late Kelly West wrote: 'The extent to which the level of hyperglycemia determines the risk of retinopathy is not all that clear.' ${ }^{1}$ At that time, the $55 \%$ of persons with type 1

diabetes in the Wisconsin Epidemiologic Study of Diabetic Retinopathy (WESDR) took only one injection of long-acting insulin a day, essentially none did self blood glucose monitoring at least once per day, and the mean glycosylated haemoglobin $\mathrm{A}_{1 \mathrm{c}}$ level for this group was $10.1 \%{ }^{2}$ The level of glycosylated haemoglobin in persons with type 2 disease, $9.0 \%$, was also high. In addition, despite data from the Diabetic Retinopathy Study that showed panretinal photocoagulation resulted in a $50 \%$ reduction in severe visual loss (5/200 or worse) in eyes with severe proliferative retinopathy compared with eyes that were randomized to no treatment, only $54 \%$ of eyes with severe proliferative retinopathy in those with type 1 diabetes and $32 \%$ of those with type 2 diabetes had had such treatment. ${ }^{3,4}$ Only $67 \%$ of those with type 1 diabetes and $50 \%$ of those with type 2 diabetes in the WESDR had been seen by an ophthalmologist within 2 years of the time they were studied in 1980-2. ${ }^{5}$

Twenty years later, the pathogenesis of diabetic retinopathy has become better understood, leading to new approaches to its treatment and prevention. ${ }^{6,7}$ Epidemiological data from population-based studies ${ }^{8}$ and clinical trials ${ }^{9-11}$ have provided an answer to Kelly West's question. Data from the Diabetes Control and Complications Trial (DCCT) showed that in persons with type 1 diabetes, intensive treatment with insulin significantly reduced the risk of progression of retinopathy by $63 \%$, of macular oedema by $26 \%$, and the need for laser treatment by $51 \%$ compared with conventional treatment. ${ }^{9}$ The WESDR showed that after adjusting for other risk factors in persons with type 2 diabetes a $1 \%$ decrease in glycosylated haemoglobin levels over the first 4 years of the study was associated with a $22 \%$ decrease in the odds of developing proliferative retinopathy and a $15 \%$ decrease in the odds of developing macular oedema at the 10-year follow-up. ${ }^{8}$ In patients with type 2 diabetes, data from the United Kingdom Diabetes Prospective Study (UKPDS) showed that compared with the conventional group, the risk reduction for progression of diabetic retinopathy over a 12-year period in the intensive group was $21 \% .{ }^{12}$ In addition, there was a $29 \%$ reduction in the need for retinal photocoagulation in the intensive compared with the conventional group.

Understanding how hyperglycaemia mediates physiological and biochemical changes in the retina has resulted in the development of new strategies aimed at prevention and treatment of diabetic retinopathy. Hyperglycaemia has been hypothesised to: activate the diacylglycerol pathway with an increase in protein kinase $C$ activity; ${ }^{13}$ increase non-enzymatic glycosylation, ${ }^{14}$ aldose reductase activity, ${ }^{15}$ and secretion of vasoactive substances such as endothelin, prostanoids, histamine and nitrous oxide; ${ }^{16}$ result in oxidant-induced free radical damage; ${ }^{17}$ and release growth factors. ${ }^{18}$ These biochemical changes have been postulated to lead to anatomical and functional changes in the retinal vasculature. The initiation and progression of retinopathy is probably due to a complex relationship among a number of these factors, that vary from person to person and at different stages of the retinopathy.

Data from the DCCT, UKPDS and epidemiological data from studies such as the WESDR resulted in the development by the American Diabetes Association of guidelines for glycaemic control in persons with type 1 and 2 diabetes. ${ }^{19}$ In addition, data from the Early Treatment Diabetic Retinopathy Study suggested that severe visual loss of $5 / 200$ could be prevented in $95 \%$ of patients with diabetes if there was early detection and timely photocoagulation treatment of clinically significant macular oedema and proliferative diabetic retinopathy. ${ }^{20,21}$ This resulted in the development of guidelines by numerous groups, including the St Vincent Declaration, ${ }^{22}$ which outlined approaches and set guidelines for early detection and timely treatment of vision-threatening diabetic retinopathy. A large body of literature has resulted describing the cost-effectiveness of such approaches, their implementation, and the success of such programmes. $^{23-25}$
Professor Ronald Klein, $\mathrm{MD}, \mathrm{MPH}$

Department of

Ophthalmology and Visual Sciences University of Wisconsin Medical School

610 North Walnut Street, 460 WARF

Madison, WI 53705-2397, USA

Tel: +1 (608) 2637758

Fax: +1 (608) 2630279 
The successful implementation of these guidelines for levels of glycaemic control has been difficult because achieving the levels of glycaemic control as recommended by the DCCT is associated with severe hypoglycaemia. ${ }^{2,9}$ Other medical approaches to preventing or reducing the progression of retinopathy, such as control of hypertension, have recently been shown to reduce the progression of diabetic retinopathy in people with diabetes. A recently completed clinical trial suggested a benefit of the ACE inhibitor, lisinopril, in reducing the progression of diabetic retinopathy in persons with type 1 diabetes. ${ }^{26}$ Tight blood pressure control resulted in a $34 \%$ reduction in the rate of progression of retinopathy, a 35\% reduction in retinal photocoagulation, and a $47 \%$ reduction in the deterioration of visual acuity by three lines or more compared with conventional control in persons with type 2 diabetes participating in the UKPDS. ${ }^{27}$ Other medical approaches to reducing the progression of retinopathy such as control of dyslipidaemia may be of benefit in reducing the incidence or microvascular and macrovascular complications. Clinical trials are under way to study the efficacy of control of dyslipidaemia and to further study the control of hypertension. ${ }^{28}$ In addition, there are also randomised clinical trials under way to study the efficacy of new drugs such as protein kinase $C$ inhibitors and anti-vascular endothelial growth factors, which may play a role in the pathogenesis of diabetic retinopathy, and clinical trials have been suggested to examine the benefits of vitamin $\mathrm{E}$ to prevent the incidence of retinopathy. If genetic susceptibility factors are found that explain variations in incidence and progression of retinopathy, then new treatments targeted to specific mechanisms administered at a specific stage in the natural history of the retinopathy might provide a complementary approach to glycaemic control in preventing the progression of retinopathy.

Implementation of educational programmes, such as those developed by the National Eye Health and Education Program, ${ }^{29}$ and developing cost-effective approaches, such as using newer computer-assisted approaches for detecting retinopathy in patients at risk for developing it, will probably result in a decline of diabetic retinopathy as an important cause of loss of visual acuity in the next century.

This research is supported by National Institutes of Health grant EYO 3083 (R. Klein, B.E.K. Klein) and, in part, by the Research to Prevent Blindness (R. Klein, Senior Scientific Investigator Award).

\section{References}

1. West KM. Epidemiology of diabetes and its vascular lesions. New York: Elsevier, 1978:415-20.

2. Klein R, Klein BEK, Moss SE, Cruickshanks KJ. The medical management of hyperglycemia over a 10 -year period in people with diabetes. Diabetes Care 1996;19:744-50.

3. Diabetic Retinopathy Study Research Group. Photocoagulation treatment of proliferative diabetic retinopathy: clinical application of Diabetic Retinopathy Study (DRS) findings. DRS report no. 8. Ophthalmology 1981;88:583-600
4. Klein R, Klein BEK, Moss SE, Davis MD, DeMets DL. The Wisconsin Epidemiologic Study of Diabetic Retinopathy. VI. Retinal photocoagulation. Ophthalmology 1987;94:747-53.

5. Witkin SR, Klein R. Ophthalmologic care for persons with diabetes. JAMA 1984;251:2534-7.

6. Frank RN. On the pathogenesis of diabetic retinopathy: a 1990 update. Ophthalmology 1991;98:586-93.

7. Klein R. Retinopathy and other ocular complications in diabetes. In: Porte D Jr, Sherwin RS, editors. Ellenberg \& Rifkin's diabetes mellitus. 5th ed. Stamford, CT: Appleton \& Lange, 1996:938-40.

8. Klein R, Klein BEK, Moss SE, Cruickshanks KJ. The relationship of hyperglycemia to the long-term incidence and progression of diabetic retinopathy. Arch Intern Med 1994;154:2169-78.

9. The DCCT Research Group. The effect of intensive treatment of diabetes on the development and progression of long-term complications in insulin-dependent diabetes mellitus. N Engl J Med 1993;329:977-86.

10. Reichard P, Nilsson B-Y, Rosenqvist U. The effects of longterm intensified insulin treatment on the development of microvascular complications of diabetes mellitus. N Engl J Med 1993;329:304-9.

11. Ohkubo Y, Kishikawa H, Araki E, et al. Intensive insulin therapy prevents the progression of diabetic microvascular complications in Japanese patients with non-insulindependent diabetes mellitus: a randomised prospective 6-year study. Diabetes Res Clin Pract 1995;28:103-17.

12. UK Prospective Diabetes Study Group. Intensive blood glucose control with sulphonylurea or insulin compared with conventional treatment and risk of complications in patients with Type 2 diabetes. UKPDS 33. Lancet 1998;352:837-53.

13. Xia P, Inoguchi T, Kern TS, Engerman RL, Oates PJ, King GL. Characterisation of the mechanism for the chronic activation of diacylglycerol-protein kinase $C$ pathway in diabetes and hypergalactosemia. Diabetes 1994;43:1122-9.

14. Brownlee M, Cerami, A, Vlassara H. Advanced glycosylation end products in tissue and the biochemical basis of diabetic complications. N Engl J Med 1988;318:1315-21.

15. Frank RN, Keirn RJ, Kennedy A, Frank KW. Galactoseinduced retinal capillary basement membrane thickening: prevention by sorbinil. Invest Ophthalmol Vis Sci 1983;24:1519-24.

16. Tilton RG, Chang K, Hasan KS, et al. Prevention of dysfunction by guanidines: inhibition of nitric oxide synthetase versus advanced glycosylated end-product formation. Diabetes 1993;42:221-32.

17. Giugliano D, Cerellio A, Paolisso G. Oxidative stress and diabetic vascular complications. Diabetes Care 1996;19:257-65.

18. Clermont AC, Aiello LP, Mori F, et al. Vascular endothelial growth factor and severity of nonproliferative diabetic retinopathy mediate retinal hemodynamics in vivo: a potential role for vascular endothelial growth factor in the progression of nonproliferative diabetic retinopathy. Am J Ophthalmol 1997;124:443-6.

19. American Diabetes Association. Position statement. Standards of medical care for patients with diabetes mellitus. Diabetes Care 1995;18(Suppl 1):8-15.

20. ETDRS Research Group. Photocoagulation for diabetic macular edema. Arch Ophthalmol 1985;103:1796-806.

21. Ferris FL III. How effective are treatments for diabetic retinopathy? JAMA 1993;269:1290-1.

22. International Diabetes Federation. Diabetes care and research in Europe: the Saint Vincent's Declaration. Diabet Med 1990;7:360.

23. Dasbach EJ, Fryback DG, Newcomb PA, et al. Costeffectiveness of strategies for detecting diabetic retinopathy. Med Care 1991;29:20-39. 
24. Javitt JC, Aiello LP. Cost-effectiveness of detecting and treating diabetic retinopathy. Ann Intern Med 1996;124:164-9.

25. Crijns H. Diabetic retinopathy: a cost-effectiveness analysis of ophthalmoscopy and photocoagulation [thesis]. Erasmus University, Amsterdam, 1993.

26. Chaturvedi N, Sjolie A-K, Stephenson JM, et al. Effect of lisinopril on progression of retinopathy in normotensive people with type 1 diabetes. Lancet 1998;351:28-31.

27. UK Prospective Diabetes Study Group. Tight blood pressure control and risk of macrovascular and microvascular complications in Type 2 diabetes. UKPDS 38. BMJ 1998;317:703-13.
28. Savage S, Johnson NL, Estacio RO, et al, The ABCD [Appropriate Blood Pressure Control in Diabetes] Trial: rationale and design of a trial of hypertension control (moderate or intensive) in Type II diabetes. Online Journal of Current Clinical Trials. Doc no. 104, 1993.

29. The National Eye Health Education Program. From vision research to eye health education: planning the partnership. Bethesda, Md: National Institutes of Health, 1990. Available from National Institutes of Health, Box 20/20, Bethesda, MD 20892, USA. 